Gut, 1983, 24; 333-339

\title{
Upper gastrointestinal tract polyps in familial adenomatosis coli
}

\author{
H JÄRVINEN, M NYBERG, AND P PELTOKALLIO \\ From the Second Department of Surgery, Helsinki University Central Hospital, and Department of \\ Pathology, University of Helsinki, Helsinki, Finland
}

SUMMARY Upper gastrointestinal tract polyps were sought prospectively using endoscopy and biopsy in 34 patients with familial adenomatosis coli belonging to 18 unrelated families. Gastric and/or duodenal polyps, usually small and multiple, occurred in 28 patients $(82 \%)$. Histologically verified extracolonic adenomas were present in 19 patients $(56 \%)$. Gastric adenomas, all in the antrum, and duodenal adenomas occurred in four $(12 \%)$ and $16(48 \%)$ patients, respectively. In one patient, a duodenal adenocarcinoma and a bile duct adenoma were also found, and one patient had an adenocarcinoma of the bile ducts. Multiple non-neoplastic polyps were found in 19 patients $(56 \%)$, most often in the stomach and also in the duodenum in 12 patients; they co-existed often with adenomas. In addition, there were nine patients with ileal polyps, most of them showing lymphoid hyperplasia but also one with adenomas. It is suggested that familial adenomatosis affects the whole gastrointestinal tract, not only the colon and rectum as believed earlier. Although upper gastrointestinal tract adenomas are not as consistent and multiple as those in the colon, and probably do not require prophylactic surgery, regular lifelong endoscopic follow up is warranted because of obviously increased cancer risk.

Upper gastrointestinal polyps have been reported occasionally in patients with familial adenomatosis coli. ${ }^{1-4}$ Such patients have been regarded as rare exceptions, and interpretation of the histology of the gastric and duodenal polyps has varied. ${ }^{5-7}$ At present, it seems that both adenomas and nonneoplastic polyps occur much more commonly in the stomach, ${ }^{8-11}$ the duodenum, ${ }^{911} 12$ and even in the jejunum and ileum, ${ }^{13} 14$ in familial adenomatosis than was previously believed. Hence, extracolonic polyposis may be an integral part of the disease but systematic studies on the occurrence of polyposis outside the colon are few, and have been restricted to a small number of patients.

The present paper reports the results of a systematic prospective search for polyps in the upper gastrointestinal tract in 34 Finnish patients with familial adenomatosis coli.

Address for correspondence: Heikki Järvinen. Second Department of Surgery. University Central Hospital. 00290 Helsinki 29. Finland.

Received for publication 14 July 1982

\section{Methods}

PATIENTS

Of the 42 patients with familial adenomatosis coli seen in our clinic, $34(81 \%)$ belonging to 18 unrelated families underwent gastroduodenoscopy or necropsy and form the material of this investigation. There were 17 men and 17 women, aged 16 to 67 years (mean 33 years). In four cases there was no family history, but even in these the colon was typically full of adenomas at surgery (three patients), or colonoscopy (one). Thirteen young patients still awaited surgery at the time of the study, but six of them were operated on at a later date; thus, 27 patients have now undergone colectomy with ileorectostomy or proctocolectomy. All but two patients were fully examined for Gardner's signs, osteomas, and soft tissue tumours; at least one of these manifestations was present in 24 patients $(71 \%)$, and in 13 of the families $(72 \%)$. The patients had no upper abdominal symptoms except one with obstructive jaundice. 
Gastroduodenoscopies (Olympus GIF-Q) were performed with few exceptions by one endoscopist, once in 22 patients, and two to five times in 11 patients. Endoscopic photographs and several biopsies were taken from all patients with polypoid lesions. The duodenum was not hypotonised, however; thus, detection and biopsy of small duodenal lesions was often difficult. In one patient only autopsy specimens of the upper gastrointestinal tract lesions were available. Seven patients underwent operative cholangiography, and in three of these common duct exploration. In 19 patients the examination and eventual biopsies of the terminal ileum were performed by one of the authors in conjunction with the operation (ileorectostomy) or rectoscopy performed after a low ileorectal anastomosis.

All histological specimens were examined by one pathologist and the findings interpreted according to principles presented by Morson and Dawson. ${ }^{15}$

\section{Results}

\section{MACROSCOPIC FINDINGS}

Gastric polyps were detected in 21 patients $(62 \%)$ from 14 families $(78 \%)$. They were always multiple, and often covered the whole gastric body and fundus (Figs 1, 2). Their size ranged from $1-8 \mathrm{~mm}$ in diameter. In the antrum polyps were less common and fewer in number, one to six in six patients, and were up to $12 \mathrm{~mm}$ in diameter (Fig. 3). In both locations the colour of the polypoid lesions did not differ clearly from the surrounding mucosa, and no erosions were found.

The first and second parts of the duodenum were examined in 33 patients; one had undergone pancreatoduodenectomy for a desmoid tumour of the duodenal mesentery. Polyps were found in 20 patients $(61 \%)$ from 14 families $(78 \%)$. The lesions were multiple and usually small, from $1-10 \mathrm{~mm}$ in diameter, but in a few cases large areas were covered (Figs 4,5). The duodenal polyps appeared slightly whitish and granular at endoscopy. Only rarely did polyps occur in the first part of the duodenum; as a rule they were located in the second part near the papilla and then gradually disappeared lower down (Fig. 6).

Bile duct polyps occurred in two patients. One had diffuse polyposis of the hepatic and common ducts, while the other had a solitary polyp in the distal common duct mimicking a gall stone in cholangiographs; but a polyp was revealed at choledochoscopy. In addition, one to a few small polypoid lesions of the terminal ileum were seen in nine patients, in five of them already at colectomy, and in the other four later during rectoscopies.
Extracolonic polyps were present in 29 of the 34 patients $(85 \%)$, and in at least one patient in all 18 families.

\section{MICROSCOPIC FINDINGS}

The histological findings of lesions detected macroscopically are summarised in Tables 1 and 2 . Multiple polyps in the gastric body and fundus in 18 patients $(53 \%)$ were hyperplastic non-neoplastic lesions (Fig. 7) similar to the 'fundic gland polyps' described by Watanabe et al. ${ }^{10}$ In the antrum, the polyps were adenomas in four of six patients (Fig. 8). In one of these, cystic glands were found beneath the adenoma. Three patients had no histological verification of the multiple gastric polyps.

Of the 20 patients with duodenal lesions 16 had duodenal adenomas. In one of these, multiple foci of severe dysplasia and one focus of invasive carcinoma (Fig. 9) were found. In addition, cystically dilated epithelial crypts were found in nine patients adjacent to adenoma(s) and in three with no adenomas (Fig. 10). There was no epithelial atypia in these cystic changes. In one patient with obvious duodenal polyps no abnormalities could be found in the biopsies. Both in the antrum and duodenum, the adenomatous changes often comprised only a small area of the removed polyp.

The bile duct polyps in two patients were neoplastic in both cases. One was a solitary adenoma of the distal common duct, while the other proved to be an adenocarcinoma. The small polypoid lesions of the ileum showed lymphatic hyperplasia in five patients, but also several adenomas were present in one. In three patients no biopsy of the ileal lesions was available.

\section{RELATIONS OF GASTRIC AND DUODENAL POLYPS TO OTHER CLINICAL DATA}

The occurrence of gastric and duodenal polyps was compared with the presence of Gardner's osteomas and/or soft tissue tumours (Table 3). Hyperplastic gastric polyps seemed not to depend on Gardner's manifestations, while adenomas in the antrum occurred only in cases with these signs. Duodenal adenomas also tended to occur more commonly, but not exclusively, in patients with these signs. Young patients still awaiting colectomy had more often hyperplastic gastric polyps than the patients already having undergone operation (Table 4). Apparent regression of hyperplastic gastric polyps was seen in two patients in repeated examinations, while a few observations suggested that duodenal adenomas tended to increase in number and size with time. Because of the small number of patients in the different age groups, gastric and duodenal polyps could not be correlated to age dependence. 
Fig. 1 Endoscopic view of small polyps in gastric fundus.

Fig. 2 Massive polyposis in the gastric fundus.
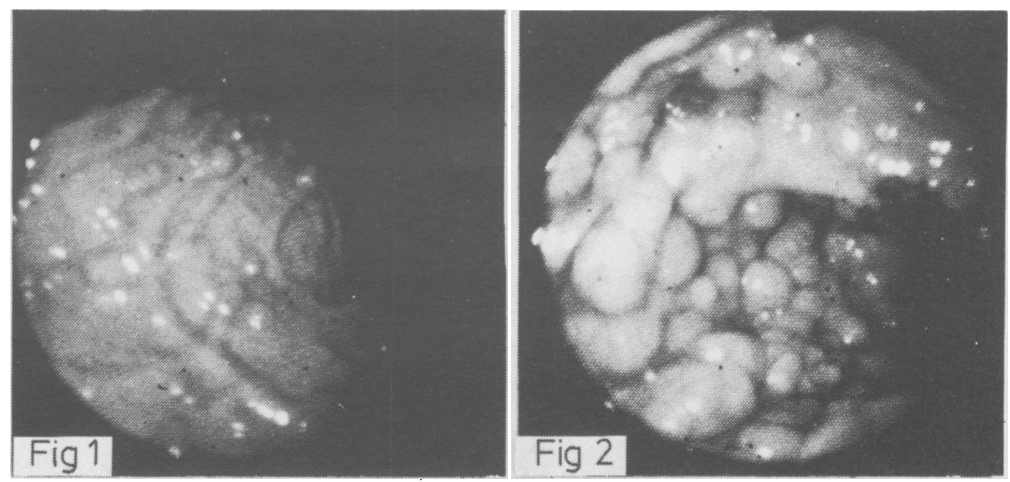

Fig. 3 Prepyloric polyps in the gastric antrum.

Fig. 4 Small duodenal polyps on endoscopy.

Fig. 5 An operative view of the duodenum carpeted with polyps. A catheter comes through the papilla of Vater. 


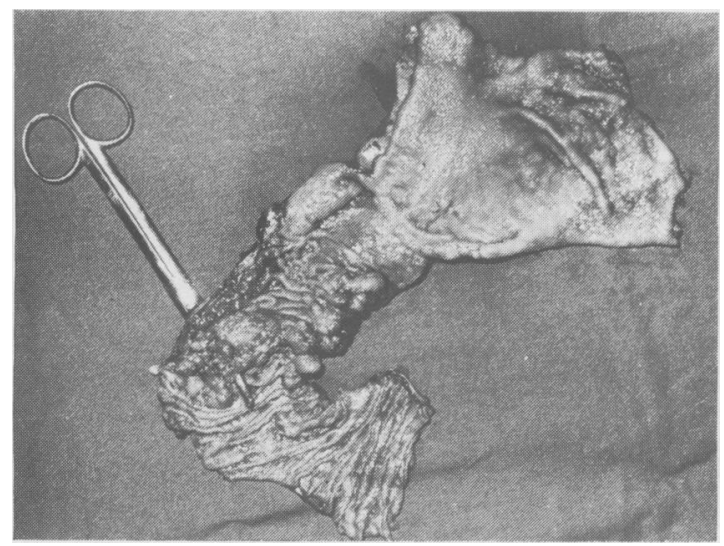

Fig. 6 Gastric antrum and duodenum of a patient with duodenal adenocarcinoma. Note concentration of polyps in second part of duodenum, and polyps near to resection line and in prepyloric area.

\section{Discussion}

The findings in the present series of patients with familial adenomatosis, the largest reported with regard to the occurrence of upper gastrointestinal tract polyps, confirm that adenomas and other polyps occur almost without exception in the stomach and duodenum in this disease; the frequency being $82 \%$ in all. Adenomas were present in $56 \%$ of patients; $12 \%$ in the gastric antrum, and $48 \%$ in the duodenum. Multiple lesions in the gastric fundus and body occurring in half of the patients were non-neoplastic hyperplastic polyps, and similar lesions were also seen in the duodenum.

The findings agree with recent reports including fewer patients, ${ }^{8-12}$ and indicate that familial adenomatosis is more a systemic disorder than a disease of the colon and rectum. The extracolonic polypous
Table 2 Summary of histological findings of extracolonic polyps irrespective of site

\begin{tabular}{lc}
\hline Histological finding & $n=34$ \\
\hline Adenoma(s) & $19(56 \%)$ \\
Adenocarcinoma & $2(5.9 \%)$ \\
Hyperplastic polyps & $19(56 \%)$ \\
Lymphoid polyps & $5(15 \%)$ \\
Polyps, no histological verification & $1(2.9 \%)$ \\
No macroscopic polyps & $5(15 \%)$ \\
\hline
\end{tabular}

involvement correlated only partially with the presence of Gardner's signs, another group of systemic symptoms. Thus, gastric polyps were not limited to cases without, and duodenal polyps not to patients with Gardner's syndrome only, as has been suspected earlier. ${ }^{16}$ In fact, simple adenomatosis coli and Gardner's syndrome are to be considered as a single genetic entity with a wide clinical spectrum. ${ }^{17}$

The observation of two patients with neoplastic bile duct polyps further supports the concept of a generalised disease. One patient cholecystectomised earlier had a solitary common duct adenoma, while the other jaundiced patient had a polypous bile duct adenocarcinoma - both rare findings in familial adenomatosis. Only two earlier reports of biliary adenocarcinomas in such patients could be found.$^{18} 19$ Ileal polyps were because of lymphoid hyperplasia in most cases, as reported earlier, ${ }^{13} 20$ but in one patient definite ileal adenomas were found. Ileal adenomas have been described also in two recent reports concerning familial adenomatosis, ${ }^{1314}$ but their frequency is unknown and probably less than that of adenomas in the duodenum and stomach.

The increasing evidence of various extracolonic manifestations in familial adenomatosis makes it difficult to find a precise term for the disease. Suggestions like familial adenomatosis coli

Table 1 Macroscopic and histological findings of extracolonic polyps in various locations

\begin{tabular}{|c|c|c|c|c|c|c|}
\hline \multirow[b]{2}{*}{ Site } & \multirow[b]{2}{*}{$\begin{array}{l}\text { Patients } \\
\text { (no.) }\end{array}$} & \multirow[b]{2}{*}{$\begin{array}{l}\text { Macroscopic } \\
\text { polyps }\end{array}$} & \multicolumn{3}{|c|}{ Histological findings } & \multirow[b]{2}{*}{$\begin{array}{l}\text { No biopsy } \\
\text { or normal }\end{array}$} \\
\hline & & & Adenoma & $\begin{array}{l}\text { Adeno- } \\
\text { carcinoma }\end{array}$ & Hyperplasia & \\
\hline \multicolumn{7}{|l|}{ Stomach } \\
\hline Body/fundus & 34 & $21(62 \%)$ & - & - & 17 & 3 \\
\hline Antrum & 33 & $6(18 \%)$ & 4 & - & 1 & 1 \\
\hline Duodenum & 33 & $20(61 \%)$ & 16 & $1^{*}$ & 3 & 1 \\
\hline Bile ducts & 7 & $2(-)$ & 1 & 1 & - & - \\
\hline Terminal ileum & 19 & $9(-)$ & 1 & - & 5 & 3 \\
\hline
\end{tabular}

* Also included in patients with adenomas. 


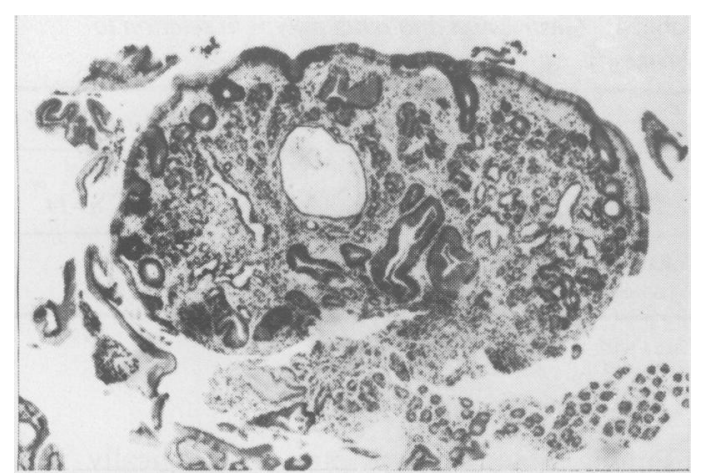

Fig. 7 Fundic gland polyp. Alcian blue-PAS stain, $\times 45$ (original magnification).

syndrome and familial gastrointestinal polyposis (adenomatosis) seem to be more adequate than the old 'familial polyposis coli'. ${ }^{10} 14$

The adenoma-carcinoma sequence has attracted much interest in the aetiological considerations of gastrointestinal cancer, and some authors believe that this sequence is followed in most, if not all, cases. ${ }^{21}$ The two extracolonic adenocarcinomas in our series fit well into this concept. It is also well

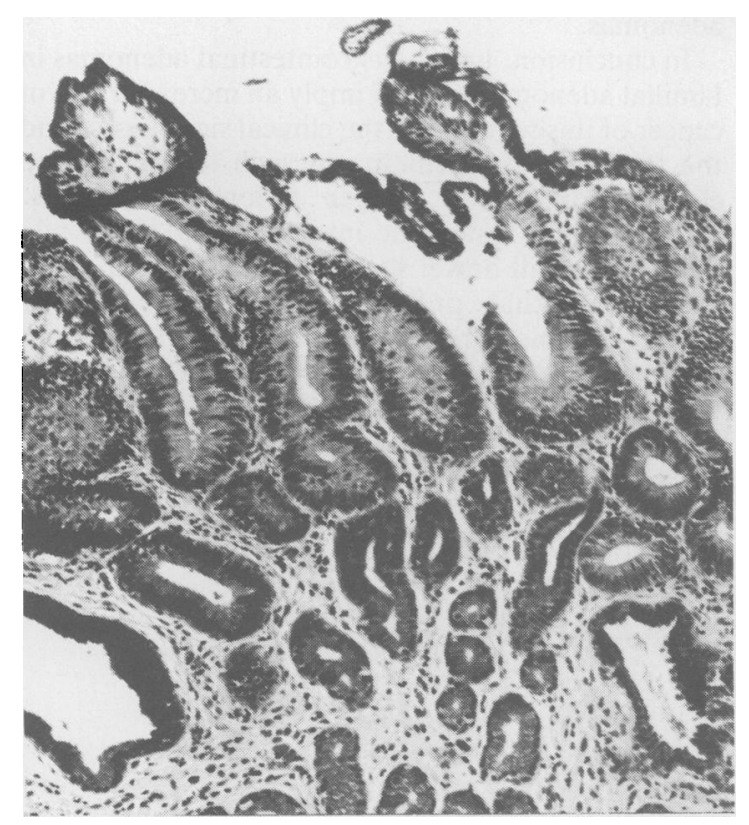

Fig. 8 Adenomatous change in antrum; normal epithelium in glands below. Alcian blue-PAS stain, $\times 115$ (original magnification).

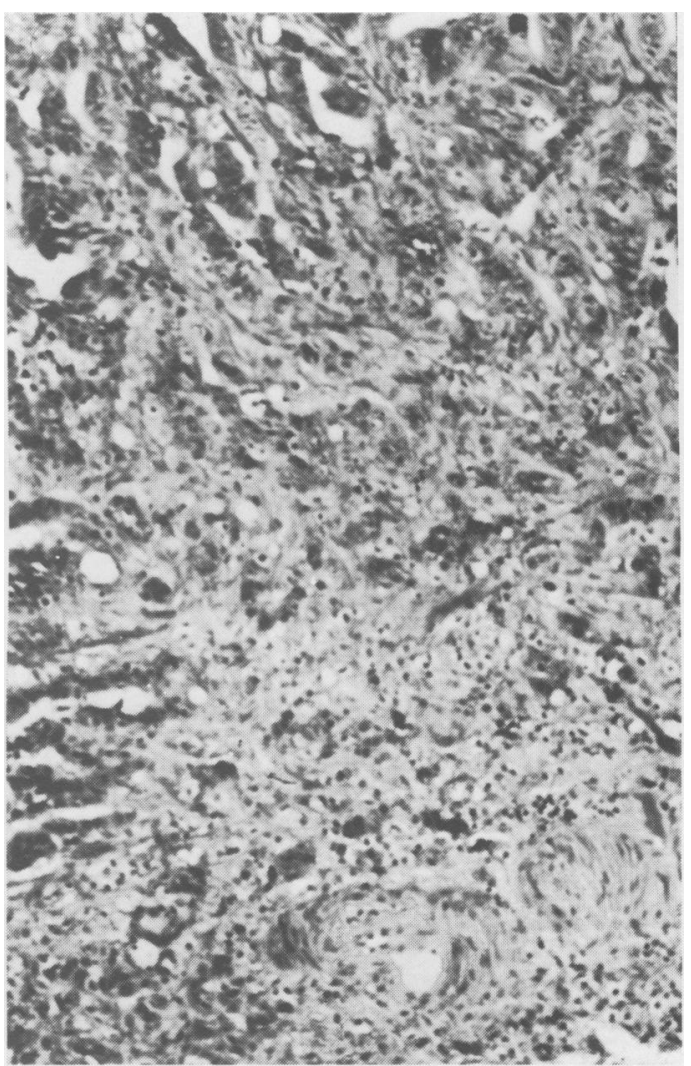

Fig. 9 Carcinoma of duodenum. Invasion adjacent to blood vessels at lower right. Van Gieson stain, $\times 115$ (original magnification).

known that duodenal cancer is the second most common malignancy in familial adenomatosis and has been reported in about 50 patients. ${ }^{7} 122223$ Watanabe et $a l^{10}$ reported three cases of gastric cancer associated with familial adenomatosis and found an additional 10 in the literature, while only a few cases of bile duct cancer (see above) or small bowel cancer are known in such patients. ${ }^{24-26}$ Thus, the distribution of upper gastrointestinal cancer in familial adenomatosis is similar to that of the adenomas, which supports the adenoma-carcinoma sequence.

The hypothesis presented by Sachatello that familial adenomatosis is an inborn error of steroid metabolism, in which an abnormal substance is excreted via the bile to the bowel, where this substance acts as a carcinogen, seems increasingly attractive. ${ }^{22} 27$ Accordingly, gastric adenomas in the antrum could be caused by this hypothetical steroid 


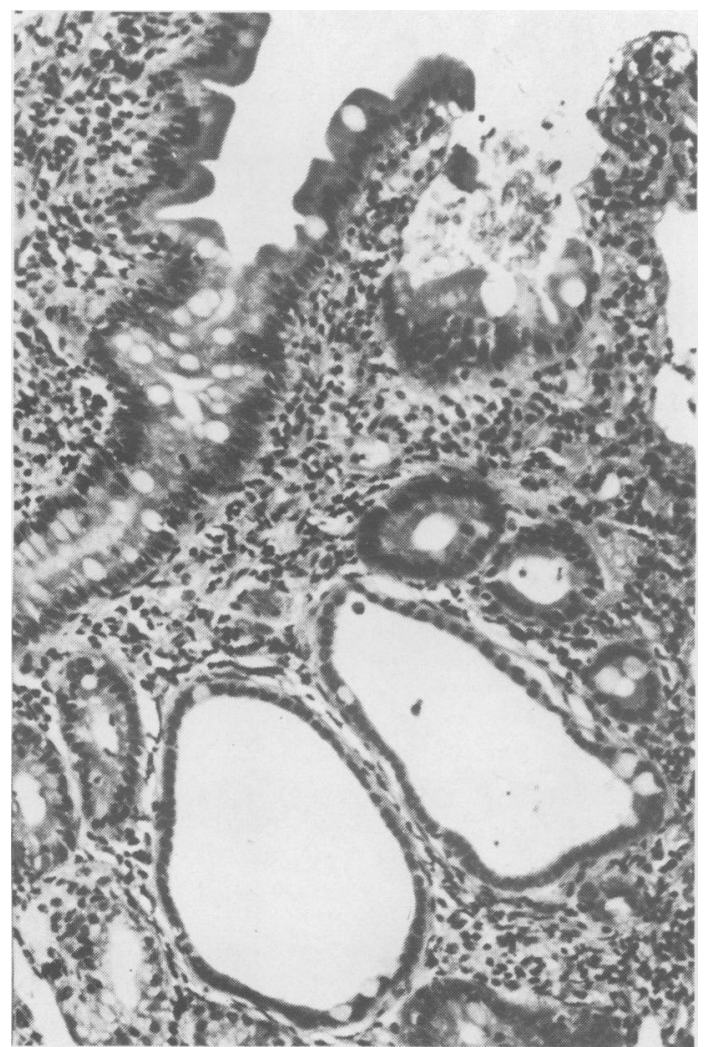

Fig. 10 Duodenal polyp; cystic crypts with flattened epithelium. Normal surface epithelium. Van Gieson stain, $\times 180$ (original magnification).

metabolite in the presence of duodenogastric reflux. Also, extraintestinal manifestations could be explained, if this metabolite participated in the enterohepatic circulation. This hypothesis is supported by observations concerning changes in faecal steroids and bile acids in familial adenomatosis. ${ }^{28} 29$

Table 3 Gastric and duodenal polyps in relation to Gardner's signs

\begin{tabular}{|c|c|c|c|c|}
\hline & \multicolumn{2}{|c|}{ Gastric polyps } & \multicolumn{2}{|c|}{ Duodenal polyps } \\
\hline & $\begin{array}{l}+ \\
n=21\end{array}$ & $\bar{n}=13$ & $\begin{array}{l}+ \\
n=20\end{array}$ & $\overline{n=14}$ \\
\hline $\begin{array}{c}\text { Gardner's signs + } \\
(n=24)\end{array}$ & $13(4)$ & 11 & $17(13)$ & 7 \\
\hline $\begin{array}{l}\text { Gardner's signs - } \\
(n=10)\end{array}$ & $8(0)$ & 2 & $3(3)$ & 7 \\
\hline
\end{tabular}

Cases with adenomas in parentheses.
Table 4 Gastric and duodenal polyps in relation to colectomy

\begin{tabular}{lllllll}
\hline & \multicolumn{2}{l}{ Gastric } & polyps & & \multicolumn{2}{c}{ Duodenal polyps } \\
\cline { 2 - 3 } \cline { 5 - 6 } \cline { 5 - 6 } & + & - & & + & - \\
& $n=21$ & $n=13$ & $n=20$ & $n=14$ \\
\hline Colectomy $(\mathrm{n}=21)$ & $11(3)$ & 10 & & $14(11)$ & 7 \\
No colectomy $(\mathrm{n}=13)$ & $10(1)$ & 3 & & $6(5)$ & 7 \\
\hline
\end{tabular}

Cases with adenomas in parentheses.

Fundic gland polyps are histologically nonneoplastic, probably hamartomatous, ${ }^{10}$ but also fit into the category of hyperplastic polyps. ${ }^{15}$ It has been suggested that they develop earlier than adenomas in the stomach of patients with familial adenomatosis, ${ }^{10}$ and they occurred slightly more often in young patients who have not undergone operation. There seems to be no reason to believe, however, that fundic gland polyps would evolve into adenomas and cancer. On the contrary, they seemed to regress with time. Another non-neoplastic lesion, the cystic mucosal change is also known in connection with adenomas in the antrum, ${ }^{10}$ but has not been reported occurring in duodenal mucosa, as was the case in 12 of our patients. They may be secondary to adenomas, but also occur as individual lesions, and may thus be precursors of duodenal adenomas.

In conclusion, upper gastrointestinal adenomas in familial adenomatosis coli imply an increased risk of cancer of this region, but the clinical significance and the true risk of carcinoma in such lesions can be clarified only after longer follow up periods. Possibly more systematic investigations of the bile ducts and small bowel should also be carried out.

We feel that prophylactic gastrectomies or duodenectomies are not warranted at the present time unless there is already suspicion of cancer. Careful gastroduodenoscopic follow up with biopsy, however, is recommended for all patients with familial adenomatosis coli.

This study was supported by a grant from the Finnish Cancer Foundations: President of the Republic J K Paasikivi Foundation.

\section{References}

1 Halsted JA, Harris EJ, Bartlett MK. Involvement of the stomach in a familial polyposis of the gastrointestinal tract. Gastroenterology 1950; 15: 763-70. 
2 Mayo CW, DeWeerd JH, Jackman RJ. Diffuse familial polyposis of the colon. Surg Gynecol Obstet 1951; 93: 87-96.

3 Parks TG, Bussey HJR, Lockhart-Mummery HE. Familial polyposis coli associated with extracolonic abnormalities. Gut 1970; 11: 323-9.

4 Hoffmann DC, Goligher JC. Polyposis of the stomach and small intestine in association with familial polyposis coli. Br J Surg 1971; 58: 126-8.

5 Duncan BR, Dohner WA, Priest JH. The Gardner syndrome: need for early diagnosis. J Pediatr 1968; 72: 497-505.

6 Bussey HJR, Veale AMO, Morson BC. Genetics of gastrointestinal polyposis. Gastroenterology 1978; 74: 1325-30.

7 Naylor EW, Lebenthal E. Gardner's syndrome. Recent developments in research and management. Dig Dis Sci 1980; 25: 945-59.

8 Utsunomiya J, Maki T, Iwama T et al. Gastric lesion of familial polyposis coli. Cancer $1974 ;$ 34: 745-54.

9 Ushio K, Sasagawa M, Doi H et al. Lesions associated with familial polyposis coli: studies of lesions of the stomach, duodenum, bones, and teeth. Gastrointest Radiol 1976; 1: 67-80.

10 Watanabe H, Enjoji M, Yao T, Ohsato K. Gastric lesions in familial adenomatosis coli. Hum Pathol 1978; 9: $269-83$.

11 Ranzi T, Castagnone D, Velio P, Bianchi P, Polli EE. Gastric and duodenal polyps in familial polyposis coli. Gut 1981; 22: 363-7.

12 Yao $\mathrm{T}$, Iida $\mathrm{M}$, Ohsato $\mathrm{K}$, Watanabe $\mathrm{H}$, Omae $\mathrm{T}$. Duodenal lesions in familial polyposis of the colon. Gastroenterology 1977; 73: 1086-92.

13 Ohsato K, Yao T, Watanabe H et al. Small intestinal involvement in familial polyposis diagnosed by operative intestinal fiberoscopy. Dis Colon Rectum 1977; 20: 414-20.

14 Hamilton SR, Bussey HJR, Mendelsohn G et al. Ileal adenomas in nine patients with adenomatous polyposis coli/Gardner's syndrome. Gastroenterology 1979; 77: 1252-7.

15 Morson BC, Dawson IMP. Gastrointestinal pathology, 2nd ed. Oxford: Blackwell, 1979.

16 Schulman A. Gastric and small bowel polyps in Gardner's syndrome and familial polyposis coli. J Can Assoc Radiol 1976; 27: 206-9.

17 Schuchardt WA, Ponsky JL. Familial polyposis and Gardner's syndrome. Surg Gynecol Obstet 1979; 148: 97-103.

18 Burney B, Assor D. Polyposis coli with adenocarcinoma associated with carcinoma in situ of the gallbladder. Am J Surg 1976; 132: 100-2.

19 Lees CD, Hermann RE. Familial polyposis coli associated with bile duct cancer. Am J Surg 1981; 141: 378-80.

20 Shull IN Jr, Fitts CT. Lymphoid polyposis associated with familial polyposis and Gardner's syndrome. Ann Surg 1974; 180: 319-22.

21 Morson BC. Evolution of cancer of the colon and rectum. Cancer 1974; 34: 845-9.

22 Sachatello CR. Familial polyposis of the colon. A four-decade follow-up. Cancer 1971; 28: 581-7.

23 Jones TR, Nance FC. Periampullary malignancy in Gardner's syndrome. Ann Surg 1977; 185: 565-73.

24 Heffernon EW, Metcalfe O, Schwarz HJ. Polyposis of the small and large bowel with carcinoma in a villous polyp of the jejunum: report of a case. Gastroenterology 1962; 42: 60-2.

25 Ross JE, Mara JE. Small bowel polyps and carcinoma in multiple intestinal polyposis. Arch Surg 1974; 108: 736-8.

26 Phillips LG Jr. Polyposis and carcinoma of the small bowel and familial colonic polyposis. Dis Colon Rectum 1981; 24: 478-81.

27 Sachatello CR, Hedgecock H, Armstrong A. What can experimental colorectal cancer tell us about colorectal cancer in man? Dis Colon Rectum 1980; 23: 80-5.

28 Reddy BS, Mastromarino A, Gustafson C, Lipkin M, Wynder EL. Fecal bile acids and neutral sterols in patients with familial polyposis. Cancer 1976; 38: 1694-8.

29 Watne AL, Lai H-YL, Mance T, Core S. Fecal steroids and bacterial flora in patients with polyposis coli. Am J Surg 1976; 131: 42-6. 